\title{
Prolonged Survival in a Patient with a Pancreatic Acinar Cell Carcinoma
}

\author{
Anne Ploquin Capucine Baldini Perrine Vuagnat Samira Makhloufi \\ Christophe Desauw Mohamed Hebbar \\ Department of Medical Oncology, University Hospital, Lille, France
}

\section{Key Words}

Pancreatic acinar cell carcinoma $\cdot$ Long-term survival $\cdot B R C A 2$ mutation

\begin{abstract}
Pancreatic acinar cell carcinoma (ACC) is a rare entity. Herein we present the case of a 50year-old male patient with an unlimited mass on the pancreatic corpus and tail with peripancreatic effusion and multiple metastases in the liver and spleen. A liver biopsy showed a pancreatic ACC. The patient received 9 cycles of gemcitabine plus oxaliplatin (GEMOX regimen), which had to be stopped because of a persistent grade 2 neuropathy. A CT scan showed complete response after 14 years. At the age of 61 years, a localized prostatic cancer was diagnosed, treated by prostatectomy. The patient carried a BRCA2 mutation. None of the precedent case reports describe a chemosensibility to the GEMOX regimen. In spite of the lack of study in these patients, chemotherapy with oxaliplatin seems to be the most effective. Long survival can be expected.

(C) 2015 The Author(s)

Published by S. Karger AG, Basel
\end{abstract}

\section{Introduction}

Prognosis of advanced or metastatic pancreatic adenocarcinoma is poor, with a median overall survival between 6.8 and 11 months for all histological types [1].

Pancreatic acinar cell carcinoma (ACC) is a rare entity. Few series have been published, mainly on patients treated by surgery $[2,3]$. Few data are available about chemosensitivity in patients with metastatic ACC. Evidence is poor, mainly based on case reports [4].

Herein we report a case of a patient treated by the combination of gemcitabine plus oxaliplatin (GEMOX regimen) with a complete radiological response.

\section{KARGER 125}


Ploquin et al.: Prolonged Survival in a Patient with a Pancreatic Acinar Cell Carcinoma

\section{Case Presentation}

A 50-year-old male complained of epigastric and right hypochondriac region pain in April 2001. Physical examination revealed a mild hepatomegaly. The patient had a good performance status (ECOG 1). No weight loss was reported.

A CT scan showed multiple cystic tumors in the liver and spleen, a pseudocystic tumor on the pancreatic isthmus and an unlimited mass on the pancreatic corpus and tail with peripancreatic effusion. There was no evidence of nodes. A liver biopsy showed an ACC. The octreoscan and tumor marker CA 19.9 concentration were normal.

In May 2001, chemotherapy with gemcitabine $1,000 \mathrm{mg} / \mathrm{m}^{2}$ and oxaliplatin $130 \mathrm{mg} / \mathrm{m}^{2}$ biweekly was started. Patient experienced grade 1 urticaria at cycle 4 and grade 2 thrombopenia, justifying a 75\% dose reduction at cycle 7. GEMOX was stopped after 9 cycles for grade 2 neuropathy.

Evaluation after 4 cycles showed partial response with a 50\% reduction of the liver and spleen tumors. After 9 cycles, a complete tumor response was obtained.

Since 2002, physical examination and biology have remained normal. CT showed no sign of relapse.

In July 2012, the initial biopsy was reanalyzed, and the initial diagnosis was confirmed.

At the age of 61 years, a localized prostatic adenocarcinoma was diagnosed, treated by radical prostatectomy.

In 2013, a personal and family history of breast cancers (sister at 34 years, mother at 60 years and the grandmother) and a bladder cancer (brother) led to a genetic consultation with $B R C A 1$ and $B R C A 2$ genetic testing. The patient as well as a cousin and his two sons were found to carry a BRCA2 mutation.

In January 2015 , the patient had no clinical symptoms, a sequelary segmentary portal hypertension and well-epithelialized varicose vein on gastroscopy and he was relapse free.

\section{Discussion}

In the literature, data on ACC are scarce. The mean age at diagnostic is 60 years, with a male preponderance $(65 \%)[3,5]$. The most common diagnosis is due to mass effect such as abdominal pain, jaundice or weight loss [6]. This tumor is often associated with pancreatic panniculitis (Weber-Christian disease), perhaps due to high serum lipase concentrations. This paraneoplastic syndrome is associated with cancer progression [7].

In three studies published, few patients had metastatic disease, and no data on chemotherapy were provided $[2,3,5]$.

Data on chemosensitivity are only available from case reports. Different regimens of chemotherapy (gemcitabine, LV5FU2, oxaliplatin, cisplatin, irinotecan, docetaxel and paclitaxel) were tested alone or in combination. Nevertheless, the combination of gemcitabine plus oxaliplatin was not investigated. Objective response rates were described with FOLFIRINOX, FOLFOX, LV5FU2-gemcitabine, LV5FU2, weekly paclitaxel and LV5FU2cisplatin [4, 8-12]. However, no complete response was observed. Combinations including LV5FU2 or oxaliplatin seem to be the most effective regimens.

ACC is associated with a better prognosis than ductal adenocarcinoma at all stages of disease. In metastatic disease, Schmidt et al. [2] described a 5-year overall survival rate of $17.2 \%$ versus $2.8 \%$ for ductal carcinoma. In unresected patients, Wisnoski et al. [5] reported an overall survival of 25 versus 3 months. The longest survival observed in the literature was 11 years compared to 14 years in our patient [13]. 
Ploquin et al.: Prolonged Survival in a Patient with a Pancreatic Acinar Cell Carcinoma

Our patient carried a BRCA2 genetic mutation. BRCA2 mutations are known to be associated with pancreatic cancer, representing $2 \%$ of the total pancreatic cancer cases $[14,15]$. This mutation is also associated with ACC [16]. Nowadays, there are ongoing trials testing PARP inhibitors that show promising results with regard to platinum-based chemotherapy regimens [15].

We reported the first case of metastatic ACC treated with the GEMOX regimen. Despite the lack of study in these patients, a chemotherapy regimen with oxaliplatin seems to be the most effective combination with long survival. In these patients, long survival can be expected.

\section{Statement of Ethics}

This case report has been written with the patient's approval.

\section{Disclosure Statement}

The authors have no conflicts of interest to declare.

\section{References}

1 Conroy T, Desseigne F, Ychou M, Bouché O, Guimbaud R, Bécouarn Y, et al: FOLFIRINOX versus gemcitabine for metastatic pancreatic cancer. N Engl J Med 2011;364:1817-1825.

-2 Schmidt CM, Matos JM, Bentrem DJ, Talamonti MS, Lillemoe KD, Bilimoria KY: Acinar cell carcinoma of the pancreas in the United States: prognostic factors and comparison to ductal adenocarcinoma. J Gastrointest Surg 2008;12:2078-2086.

-3 Kitagami H, Kondo S, Hirano S, Kawakami H, Egawa S, Tanaka M: Acinar cell carcinoma of the pancreas: clinical analysis of 115 patients from Pancreatic Cancer Registry of Japan Pancreas Society. Pancreas 2007;35:42-46.

4 Simon M, Bioulac-Sage P, Trillaud H, Blanc J-F: FOLFOX regimen in pancreatic acinar cell carcinoma: case report and review of the literature. Acta Oncol 2012;51:403-405.

5 Wisnoski NC, Townsend CM, Nealon WH, Freeman JL, Riall TS: 672 patients with acinar cell carcinoma of the pancreas: a population-based comparison to pancreatic adenocarcinoma. Surgery 2008;144:141-148.

6 Yu R, Jih L, Zhai J, Nissen NN, Colquhoun S, Wolin E, et al: Mixed acinar-endocrine carcinoma of the pancreas: new clinical and pathological features in a contemporary series. Pancreas 2013;42:429-435.

7 Martin SK, Agarwal G, Lynch GR: Subcutaneous fat necrosis as the presenting feature of a pancreatic carcinoma: the challenge of differentiating endocrine and acinar pancreatic neoplasms. Pancreas 2009;38:219-222.

-8 Corbinais S, Egreteau J, Garin L, Derrien G, Boucher E, Raoul J-L: Acinous-cell carcinoma of a metastatic pancreas treated by chemotherapy (in French). Gastroenterol Clin Biol 2002;26:1180-1181.

-9 Schempf U, Sipos B, König C, Malek NP, Bitzer M, Plentz RR: FOLFIRINOX as first-line treatment for unresectable acinar cell carcinoma of the pancreas: a case report. Z Gastroenterol 2014;52:200-203.

-10 Sorscher SM: Metastatic acinar cell carcinoma of the pancreas responding to gemcitabine, 5-fluorouracil and leucovorin therapy: a case report. Eur J Cancer Care (Engl) 2009;18:318-319.

-11 Distler M, Rückert F, Dittert DD, Stroszczynski C, Dobrowolski F, Kersting S, et al: Curative resection of a primarily unresectable acinar cell carcinoma of the pancreas after chemotherapy. World J Surg Oncol 2009;7:22.

12 Riechelmann RP, Hoff PM, Moron RA, da Câmera Lopes LH, Buzaid AC: Acinar cell carcinoma of the pancreas. Int J Gastrointest Cancer 2003;34:67-72.

13 Cananzi FCM, Jayanth A, Lorenzi B, Belgaumkar A, Mochlinski K, Sharma A, et al: 'Chronic' metastatic pancreatic acinar cell carcinoma. Pancreatology 2013;13:549-552. 


\section{Case Reports in Oncology}

\begin{tabular}{l|l|}
\hline Case Rep Oncol 2015;8:447-450 \\
\hline DOI: 10.1159/000441414 & $\begin{array}{l}\text { @ } 2015 \text { The Author(s). Published by S. Karger AG, Basel } \\
\text { www.karger.com/cro }\end{array}$ \\
\hline
\end{tabular}

Ploquin et al.: Prolonged Survival in a Patient with a Pancreatic Acinar Cell Carcinoma

14 Mersch J, Jackson MA, Park M, Nebgen D, Peterson SK, Singletary C, et al: Cancers associated with BRCA1 and BRCA2 mutations other than breast and ovarian. Cancer 2015;121:269-275.

Bhalla A, Saif MW: PARP-inhibitors in BRCA-associated pancreatic cancer. JOP 2014;15:340-343.

Furukawa T, Sakamoto H, Takeuchi S, Ameri M, Kuboki Y, Yamamoto T, et al: Whole exome sequencing reveals recurrent mutations in BRCA2 and FAT genes in acinar cell carcinomas of the pancreas. Sci Rep 2015;5:8829. 